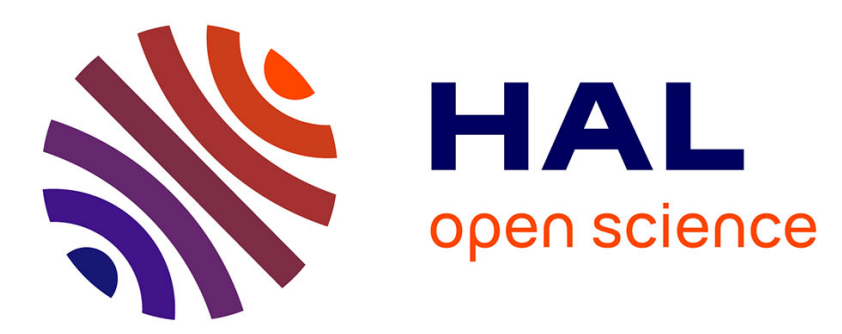

\title{
Effect of fluid viscosity and saturation on the ultrasonic velocities in a Fontainebleau sandstone
}

\author{
Azar Khalatbari, Dung Vo-Thanh, Jean-Paul Poirier
}

\section{To cite this version:}

Azar Khalatbari, Dung Vo-Thanh, Jean-Paul Poirier. Effect of fluid viscosity and saturation on the ultrasonic velocities in a Fontainebleau sandstone. Geophysical Research Letters, 1991, 18 (5), pp.885888. 10.1029/91GL01067 . insu-01733635

\section{HAL Id: insu-01733635 \\ https://hal-insu.archives-ouvertes.fr/insu-01733635}

Submitted on 14 Mar 2018

HAL is a multi-disciplinary open access archive for the deposit and dissemination of scientific research documents, whether they are published or not. The documents may come from teaching and research institutions in France or abroad, or from public or private research centers.
L'archive ouverte pluridisciplinaire HAL, est destinée au dépôt et à la diffusion de documents scientifiques de niveau recherche, publiés ou non, émanant des établissements d'enseignement et de recherche français ou étrangers, des laboratoires publics ou privés. 


\title{
EFFECT OF FLUID VISCOSITY AND SATURATION ON THE ULTRASONIC VELOCITIES IN A FONTAINEBLEAU SANDSTONE
}

\author{
Azar Khalatbari, Dung Vo-Thanh and Jean-Paul Poirier
}

Département des Géomatériaux, Institut de Physique du Globe de Paris, France

\begin{abstract}
Simultaneous measurements of the P- and Swave velocities at $1 \mathrm{MHz}$ frequency as a function of temperature from $-80^{\circ} \mathrm{C}$ to $80^{\circ} \mathrm{C}$ have been made in a Fontainebleau sandstone saturated with glycerol. We investigated 8 saturation degrees, from fully saturated to almost dry state. Generally, the velocity decreases with increasing temperature; it is large between $\approx-40^{\circ} \mathrm{C}$ and $\approx$ $40^{\circ} \mathrm{C}$. The velocity dispersion is attributed to viscous shear relaxation. The model of O'Connell and Budiansky modified by introducing the saturation parameter and a Gaussian distribution of crack aspect ratios is used to interpret the data: A trial and error method is used to estimate the model parameters. The model satisfactorily accounts for the data at high saturation.
\end{abstract}

\section{Introduction}

The laboratory measurements of the P- and S-wave velocities in rocks are important as tools for obtaining detailed information about the subsurface from seismic data. In order to give a lithological and petrophysical interpretation of seismic data, it is interesting to explore the control factors and to understand the physical laws which govern the variation of elastic parameters.

Waves propagating through a rock sample are sensitive to numerous factors; among them, the fluid viscosity plays a dominant role on the attenuation and velocity in glycerol saturated Barre granite at $0.5 \mathrm{MHz}$ frequency (Nur and Simmons, 1969) and in sandstones in the KHz frequency range (Tittmann et al., 1984; Vo-Thanh, 1990 and 1991). In this paper, we investigate the influence of fluid viscosity and saturation state on the P- and S-ultrasonic wave velocities in a Fontainebleau sandstone saturated with glycerol. The change of viscosity is made by varying the temperature from $-80^{\circ} \mathrm{C}$ to $80^{\circ} \mathrm{C}$.

It is generally accepted that the dominant mechanism responsible for seismic-wave attenuation and velocity dispersion is local fluid flow (squirt flow at low frequency and viscous shear relaxation at high frequency). The viscous shear relaxation mechanism proposed by O'Connell and Budiansky (1977) is used to interpret our results. By introducing the saturation parameter and using a Gaussian distribution of crack aspect ratios, we numerically calculated the bulk and shear modulus of saturated rocks, We used a trial and error method (Tarantola, 1987) to estimate the crack density $\varepsilon$, the central aspect ratio $\alpha_{0}$ of cracks and the standard deviation $\sigma$ of the Gaussian distribution of crack aspect ratios.

\section{Experimental Method}

The measurements were performed using a classical pulse transmission technique. Figure 1 shows the experimental setup comprising the sample, two aluminum buffers and two identical $1 \mathrm{MHz}$ PZT shear-transducers. The best coupling was obtained by glueing the aluminum buffers to the sample

Copyright 1991 by the American Geophysical Union.

Paper number 91GL01067

0094-8534/91/91GL-01067\$03.00

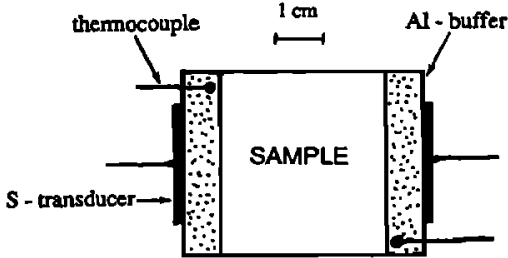

Fig.1 Experimental set-up for ultrasonic velocity measurements.

with a thin layer of Armstrong A 271 glue, and to the transducer, with a thin layer of Getelec 12008 silver epoxy resin.

The input signal was delivered by a Panametrics 5052 PR pulse generator. The transit times of the $S$-wave and of the $S$ converted to P-wave were directly measured on the screen of the Tektronic 2445 A oscilloscope by two cursors. Thus, $V_{p}$ and $V_{s}$ can simultaneous be determined in identical experimental conditions using a pair of S-transducers only.

One cylindrical sample of a Fontainebleau sandstone (40 $\mathrm{mm}$ in diameter and $35 \mathrm{~mm}$ in length) was used in this study. It is a very pure ( $>99 \%$ quartz) clay-free sandstone composed of well-rounded quartz grains, about $0.25 \mathrm{~mm}$ in diameter, cemented by silica. Its open porosity, measured by water saturation under vacuum, was about $5 \%$. Its permeability, measured using an air permeameter, was less than $1 \mathrm{mD}$. An epoxy resin replica of the pore space was observed in Scanning Electron Microscopy (Figure 2) revealing the highly interconnected nature of the pore space.

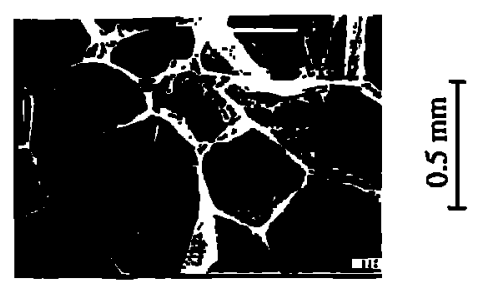

Fig. 2 Scanning electron micrograph of the epoxy pore cast of a Fontainebleau sandstone. Porosity is in the form of flat intergranular cracks and pores at the triple junctions.

The sample was first oven-dried for at least $48 \mathrm{~h}$ at $70^{\circ} \mathrm{C}$, cooled to room temperature and placed in a container under dynamic vacuum ( 0.01 torr) for $5 \mathrm{~h}$. The container was then filled with distilled glycerol (Prolabo, ref. 24 388.320) and kept in the oven at $70^{\circ} \mathrm{C}$ for $12 \mathrm{~h}$, allowing air bubbles to escape; it was then cooled to room temperature, completely filled with glycerol, closed shut and heated again to $70^{\circ} \mathrm{C}$ for $12 \mathrm{~h}$ to build up some pressure (about $40 \mathrm{bar}$ ). The sample was then cooled down, jacketed with teflon tape and transferred to the measurement apparatus. After the velocity measurements at full saturation, the unjacketed sample was placed in the oven at $70^{\circ} \mathrm{C}$ for several days, reducing the saturation state, until the required saturation level was obtained. Knowing the porosity, the glycerol saturation $S$ was calculated from the saturated and dry weights. The velocities were measured again. The process was repeated 8 
times, progressively bringing the sample from fully saturated to almost dry state.

The experiments were performed by increasing the temperature from $-80^{\circ} \mathrm{C}$ to $80^{\circ} \mathrm{C}$ at a given glycerol saturation $\mathrm{S}$. Glycerol evaporation is negligible, less than $1 \%$, during the experiment. The viscosity of glycerol strongly varies with temperature, from $\approx 10^{9}$ poise at $-80^{\circ} \mathrm{C}$ to $\approx 10^{-1}$ poise at $100^{\circ} \mathrm{C}$ (Figure 3, data from Weast, 1967). Each measurement was taken when thermal equilibrium has been obtained in the vessel, containing the sample placed inside a thermally isolated cylindrical metallic tubing. Temperatures were measured using two copper-constantan thermocouples glued to the aluminum buffers, near the sample surface (Figure 1).

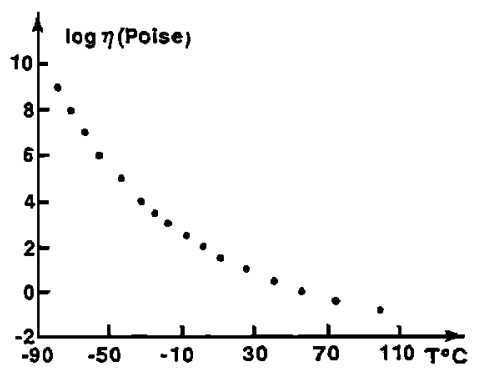

Fig. 3 Temperature dependence of glycerol viscosity (data from Weast, 1967).

The temperature gradient between the two ends of the sample was less than $1^{\circ} \mathrm{C}$. The low temperatures were obtained by running liquid nitrogen and the high temperatures by winding a resistance heater around the metallic tubing.

The length of the sample was measured to within 0.02 $\mathrm{mm}$. The signal was good at low temperature and at high saturation, it progressively degraded with increasing temperature and decreasing saturation. The transit time was measured on the screen of the scope with an accuracy better than $0.2 \mu \mathrm{s}$. It was corrected of the transit time in the aluminum buffers. The wave velocities were then known to within about $50 \mathrm{~m} / \mathrm{s}-150 \mathrm{~m} / \mathrm{s}$, depending on the temperature and saturation degree.

\section{Experimental Results}

\section{Results}

Curves A, B, C, D, E, F, G and $\mathrm{H}$ of Figures 4 (for $\mathrm{V}_{\mathrm{B}}$ ) and 5 (for $V_{S}$ ) correspond to saturation degrees $S=1,0.8$, $0.7,0.6,0.5,0.35,0.25$ and almost 0 , respectively. Generally, we observe that the shapes of $V_{p}=f(T)$ and $V_{s}=$ $f(T)$ curves are almost the same for various saturation degrees. The velocities decrease as temperature increases. The decrease is not monotonous; it is small at low temperatures, from $-80^{\circ} \mathrm{C}$ to $=-40^{\circ} \mathrm{C}$, and at high temperatures, from $\approx$ $40^{\circ} \mathrm{C}$ to $80^{\circ} \mathrm{C}$; it is large between $\approx-40^{\circ} \mathrm{C}$ and $=40^{\circ} \mathrm{C}$. The difference of the limiting velocities (between $-80^{\circ} \mathrm{C}$ and $80^{\circ} \mathrm{C}$ ) decreases as saturation decreases.

For "dry" sample, $V_{p}$ decreases from $\approx 4800 \mathrm{~m} / \mathrm{s}$ at $-80^{\circ} \mathrm{C}$ to $\approx 4500 \mathrm{~m} / \mathrm{s}$ at $80^{\circ} \mathrm{C}$ (Figure $4 \mathrm{H}$ ). In this experiment, the "dry" sample was obtained after drying the pore glycerol by heating. Small amount of glycerol undetectable by weighing may still remain in the sample, especially in cracks; this may explain the relatively large variations of $V_{p}$ and $V_{s}$ (Figures $4 \mathrm{H}$ and $5 \mathrm{H}$ ). In fact, the measurements in an another dry sample of the same Fontainebleau sandstone (Khalatbari, 1989) show that $V_{p}$ linearly decreases by about $50 \mathrm{~m} / \mathrm{s}$ in the same temperature range.

\section{Discussion}

Numerous loss mechanisms are proposed for saturated rocks. Among them, the solid-fluid inertial coupling (Biot,

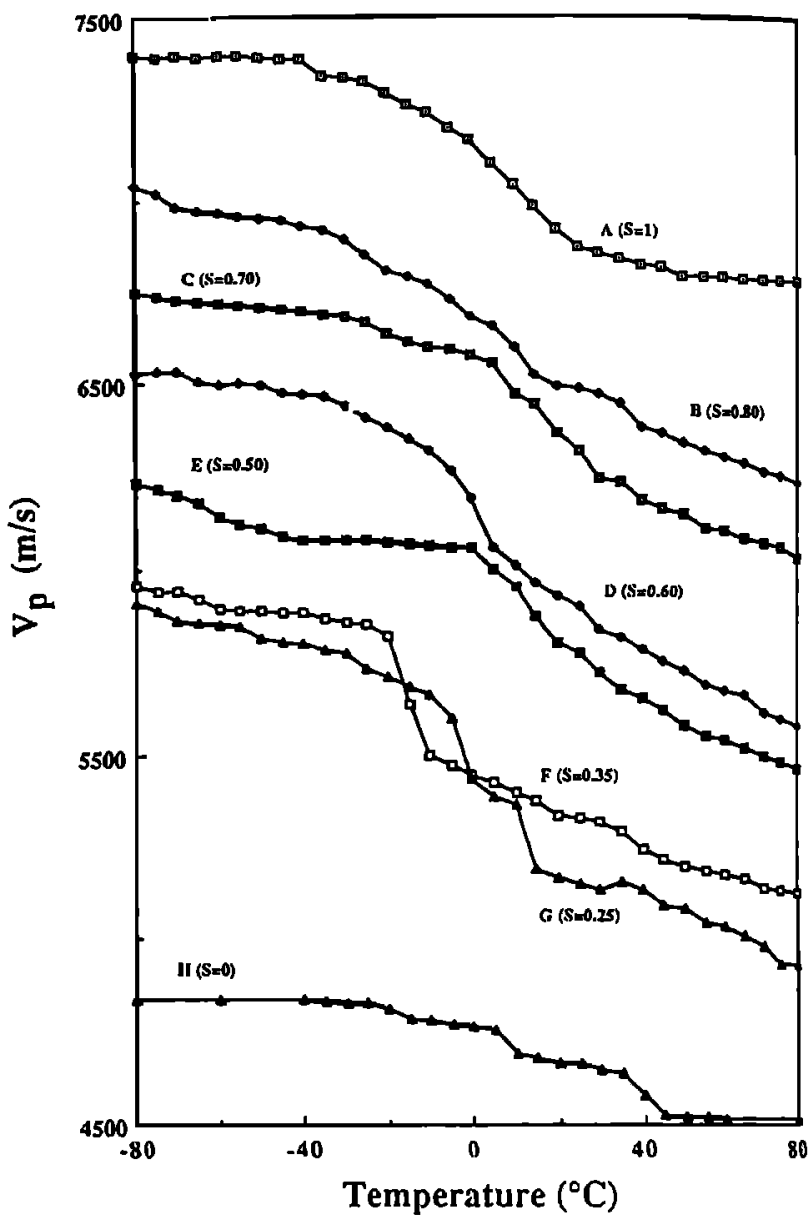

Fig. 4 Compressional velocity measured as a function of temperature in Fontainebleau sandstone saturated with glycerol. Each curve corresponds to a given saturation S. The velocity origin is for the "dry" sample (curve $H$ ); the origin of each adjacent curve is shifted by $200 \mathrm{~m} / \mathrm{s}$.

1956a, 1956b) and the local flow (squirt flow at low frequency and viscous shear relaxation at high frequency) principally developed by O'Connell and Budiansky, 1977, are usually cited as two possible mechanisms.

The characteristic frequency $f_{c}$ of the solid-fluid inertial coupling mechanism is given by

$$
\mathrm{f}_{\mathrm{c}}=\frac{\phi \eta}{2 \pi k \rho_{\mathrm{f}}}
$$

where $\eta$ and $\rho_{f}$ are the viscosity and density of pore fluid, $\phi$ and $K$ are the porosity and permeability of the rock sample (Bourbié et al., 1986). $\mathrm{f}_{\mathrm{c}} \approx 240 \mathrm{MHz}$ in our Fontainebleau sandstone at $80^{\circ} \mathrm{C}$ where the glycerol viscosity $\eta \approx 0.3$ poise. It is obvious that $f_{c}>240 \mathrm{MHz}$ when $\mathrm{T}<80^{\circ} \mathrm{C}$. According to Biot (1956a), $V_{p}$ and $V_{s}$ are constant when the glycerol viscosity varies between $-80^{\circ} \mathrm{C}$ and $80^{\circ} \mathrm{C}$ because the wave frequency ( $1 \mathrm{MHz}$ ) is too small in comparison with $f_{c}$. Therefore, Biot's solid-fluid inertial coupling cannot account for our observations.

In the local flow model (O'Connell and Budiansky, 1977) the characteristic viscosity-frequencies $\eta \omega_{1}$ of the squirt flow and $\eta \omega_{2}$ of the viscous shear attenuation peaks are approximately given as

$$
\eta \omega_{1} \approx \mathrm{K}_{\mathrm{u}} \alpha^{3}
$$




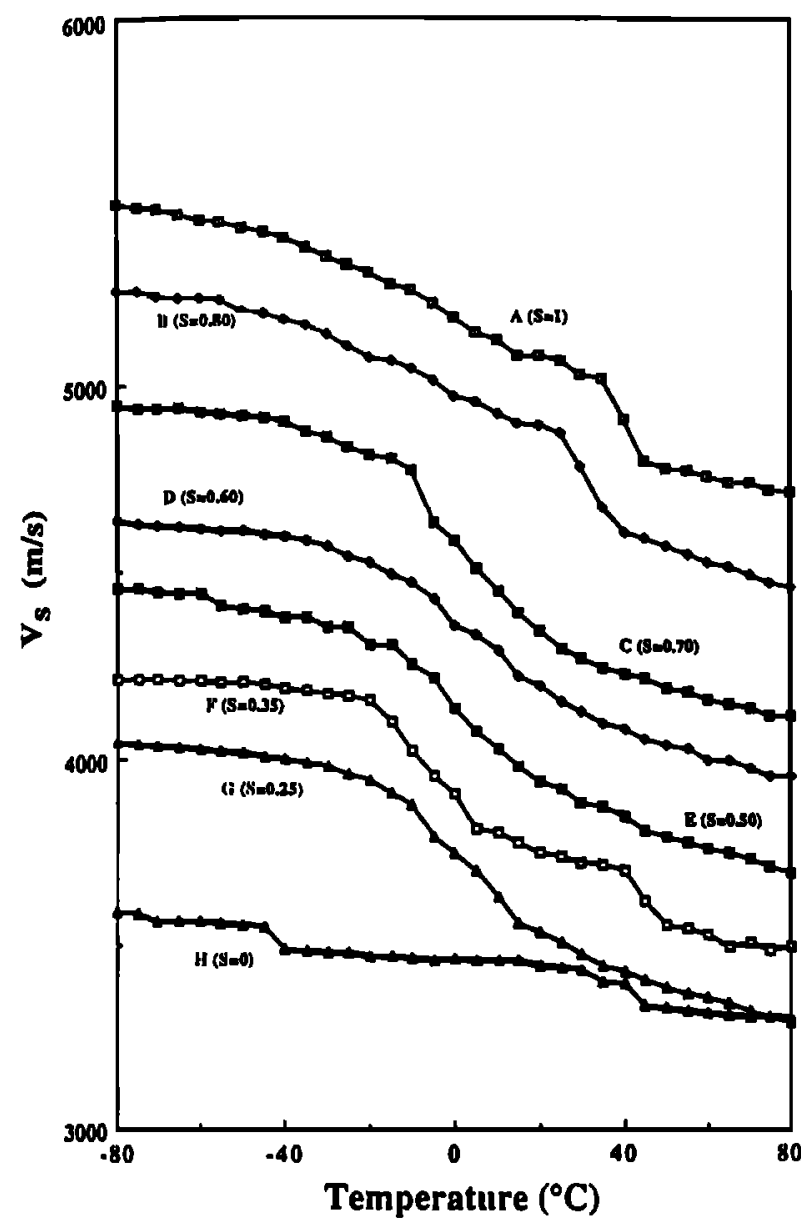

Fig. 5 Shear velocity measured as a function of temperanure in Fontainebleau sandstone saturated with glycerol. Each curve corresponds to a given saturation $S$. The velocity origin is for the "dry" sample (curve H); the origin of each adjacent curve is shifted by $200 \mathrm{~m} / \mathrm{s}$.

\section{$\eta \omega_{2} \approx \mathrm{G}_{\mathrm{u}} \alpha$}

where $\alpha$ is the crack aspect ratio; $K_{u}$ and $G_{n}$ are the bulk and shear modulus of the uncracked solid. For sandstones, the attenuation peak of squirt flow is predicted between $\mathrm{Hz}$-poise and KHz-poise and observed by Jones and Nur (1983) at $\approx$ $20 \mathrm{~Hz}$-poise, by Titmann et al. (1984) at $\approx 10^{2} \mathrm{~Hz}$-poise and by Vo-Thanh (1990) at $10^{3}-10^{4} \mathrm{~Hz}$-poise. The attenuation peak of viscous shear relaxation is predicted in the MHz-poise range and observed by Vo-Thanh (1990) at $10^{8}-10^{9} \mathrm{~Hz}-$ poise. Our data range from $10^{5.5}$ to $10^{15} \mathrm{~Hz}$-poise (Figures 6 and 7); We therefore propose using the viscous shear relaxation mechanism to interpret our data. We note finally that, between $-77^{\circ} \mathrm{C}$ and $100^{\circ} \mathrm{C}$ and using almost the same experimental method, Nur and Simmons (1969) observed a large dispersion of $V_{p}$ and $V_{s}$ near $\eta \approx 0.5$ poise in Barre granite saturated with glycerol. They suggested that the viscous shear relaxation mechanism proposed by Walsh (1969) is the origin of the velocity dispersion.

\section{Viscoelastic Model}

If a fraction $S$ of cracks is saturated, the complex elastic moduli $\vec{M}_{p}$ in partially saturated rocks can be written as (Budiansky and O'Connell, 1976)
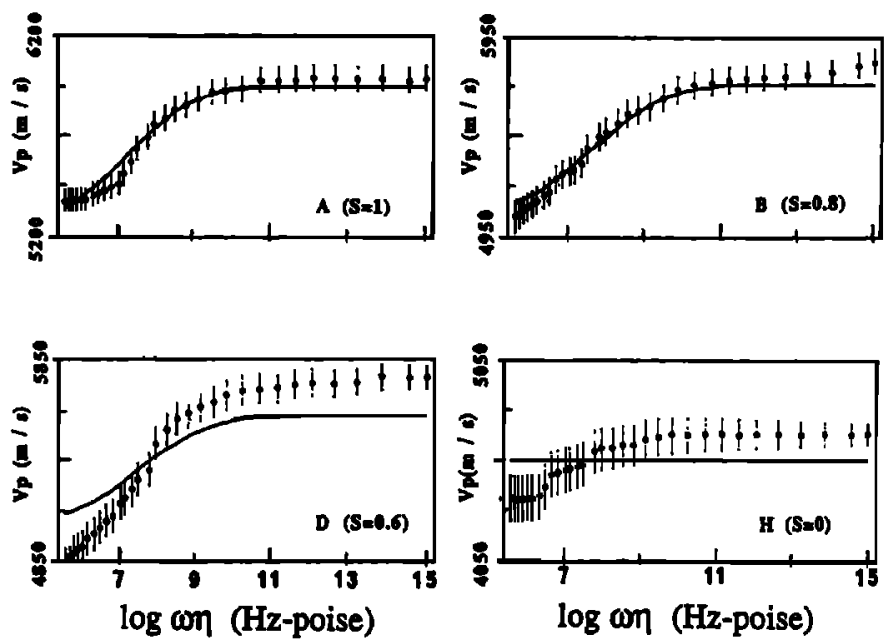

Fig. 6 Compressional velocity versus the wave frequency times pore fluid viscosity in a Fontainebleau sandstone. Each curve corresponds to a given saturation S. Bars correspond to the data, derived from Figure 4. Solid curves are model predictions, calculated for $\varepsilon=0.35, \alpha_{n}=10^{-4}, \sigma=2$.
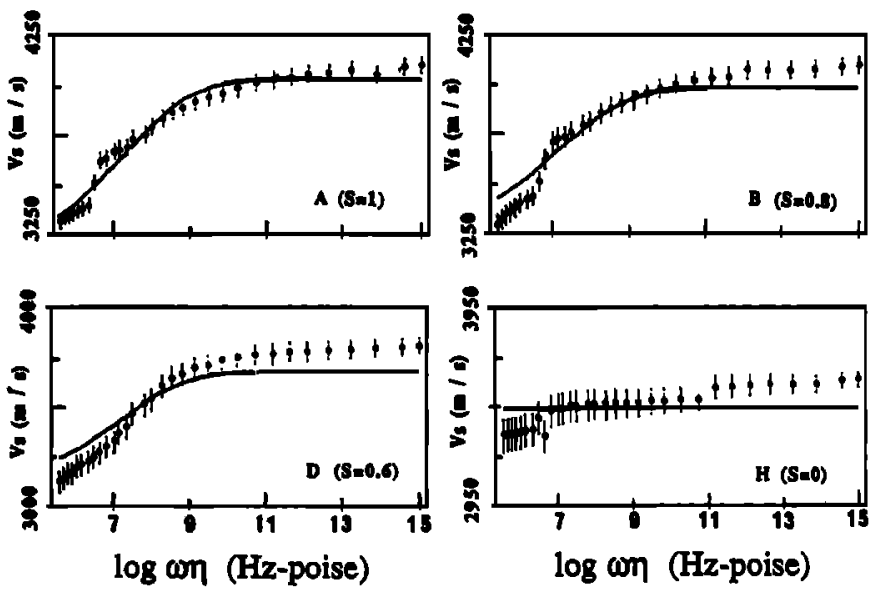

Fig. 7 Shear velocity versus the wave frequency times pore fluid viscosity in a Fontainebleau sandstone. Each curve corresponds to a given saturation S. Bars correspond to the data, derived from Figure 5. Solid curves are model predictions, calculated for $\varepsilon=0.35, \sigma=2, \alpha_{0}=10^{-4}$.

$$
\overline{\mathrm{M}}_{\mathrm{p}}=S \overline{\mathrm{M}}_{\mathrm{f}}+(1-\mathrm{S}) \overline{\mathrm{M}}_{\mathrm{d}}
$$

where the indices $p, f$ and $d$ refer to partially saturated, fully saturated and dry samples, respectively.

For partial saturation we assume that the saturation in cracks is the same as the bulk saturation; we discuss the validity of this assumption later.

As pointed out, the velocity dispersion observed in glycerol saturated sandstone (Figures 4 and 5) is attributed to viscous shear relaxation. The contribution of squirt flow is therefore ignored in the present paper.

The bulk $K_{p}$ and shear $G_{p}$ moduli in partially saturated rocks for viscous shear relaxation are given by

$$
\frac{\bar{K}_{p}}{K_{u}}=s+(1-s)\left[1-\frac{16\left(1-v^{2}\right)}{9(1-2 v)} \varepsilon\right]
$$




$$
\frac{\bar{G}_{p}}{G_{u}}=S\left[1-\frac{32\left(1-v^{\prime}\right)}{15\left(2-v^{\prime}\right)} C \varepsilon\right]+(1-S)\left[1-\frac{32(1-v)(5 v)}{45(2-v)} \varepsilon\right]
$$

where $\varepsilon$ is the crack density of the sample; $v, v^{\prime}$ and $C$ are functions of $S, \varepsilon, \eta, \omega_{2}, \bar{G}_{p}, G_{u}$, the angular wave frequency $\omega$ and the Poisson's ratio of the uncracked solid $v_{u}$ (O'Connell and Budiansky, 1977).

Discrete characteristic frequency would not be expected in rocks, owing to variability in crack shapes and widths and to various interconnections between cracks. A logarithmic Gaussian distribution $F(\alpha)$ of crack aspect ratios may be appropriate in many cases ( cf. Nowick and Berry, 1972)

$$
F(\alpha)=\frac{1}{\sigma \sqrt{2 \pi}} \exp \left[-\frac{\left(\log \alpha-\log \alpha_{0}\right)^{2}}{2 \sigma^{2}}\right]
$$

where $\alpha_{0}$ is the central aspect ratio of cracks and $\sigma$ is the standard deviation of the distribution of crack aspect ratios. The real parts of the effective moduli in partially saturated rocks can be written as

$$
\begin{aligned}
\left\langle\mathrm{G}_{\mathrm{p}}\right\rangle & =\int \mathrm{F}(\alpha) \mathrm{G}_{\mathrm{p}}(\alpha) \mathrm{d \alpha} \\
\left.<\mathrm{K}_{\mathrm{p}}\right\rangle & =\int \mathrm{F}(\alpha) \mathrm{K}_{\mathrm{p}}(\alpha) \mathrm{d} \alpha
\end{aligned}
$$

\section{Interpretation of the Results}

To estimate the three model parameters $\varepsilon, \sigma$ and $\alpha_{0}$ we used a trial and error method (Tarantola, 1987) in order to minimize the cost function $D(S)$, defined as

$$
D(S)=\sum_{\omega \eta} \frac{\left(V_{\exp }-V_{c a l}\right)^{2}}{\left(\delta_{\exp }\right)^{2}}
$$

where $V_{\text {exp }}$ and $V_{c a l}$ are the experimental and calculated velocities, respectively, and $\delta_{\exp }$ is the experimental error. $\delta_{\text {exp }}$ increases with decreasing saturation and increasing temperature. The three-parameter space $\varepsilon(0<\varepsilon<0.56), \alpha_{0}$ ( $\left.10^{-6}<\alpha_{0}<10^{-1}\right)$ and $\sigma(0<\sigma<3)$ was systematically explored.

The crack density, the central aspect ratio of cracks and the standird deviation of the distribution of crack aspect ratios found for the sample are $\varepsilon \approx 0.35, \alpha_{0} \approx 10^{-4}, \sigma \approx 2$, respectively. These values minimize the $D(S)$ functions. They are consistent with the SEM observation of the replica (Figure 2). Flit intergranular cracks account for the narrow distribution $(\sigma \approx 2)$ and low crack aspect ratio $\left(\alpha_{0} \approx 10^{-4}\right)$. Using these estimated parameters we recalculate $V_{p}$ and $V_{s}$ from Equations (8) and (9). Figures 6 and 7 show the comparison between data, derived from Figures 4 and 5, and calculations for $V_{p}$ and $V_{s}$ as a function of $\eta \omega$ at $S=1, S=$ $0.8, S=0.6$, and $S=0$, respectively. The agreement is good at high saturation; the divergence increases with decreasing saturation. This is because the global saturation in the rock sample is probably not representative of that in cracks. In fact, the reduction in saturation is performed by heating which favors the evaporation in large pores over that in cracks beciuse of the capillary forces in cracks. The saturation in cracks is then underestimated.

Acknowledgments. We gratefully acknowledge the inviluable help that Bernard Zinszner and the I. F. P. laburatory of Rock Physics gave us in the course of this work. IPG contribution $N^{\circ} 1167$.

\section{References}

Biol, M. A., Theory of propagation of elastic waves in a fluid-saturated porous solid; I. Lower frequency range, $L$ Acoust. Soc, Am, 28, 168-178, 1956 a.

Biot, M.A., Theory of propagation of elastic waves in a fluidsaturated porous solid; II. Higher frequency range, I Acoust. Soc. Am. 28 179-191, 1956 b.

Bourbié, T., Coussy, O., and Zinszner, B., Acoustique des milieux poreux, 339pp., Technip, Paris, 1986.

Budiansky, B., and O'Connell, R. J., Elastic moduli of a cracked solid, Int. J. Solids Structures. 12, 81-97, 1976.

Jones, T. D., and Nur, A., Velocity and attenuation in sandstone at elevated temperatures and pressures, Geophys. Res. Lett. 10, 140-143, 1983.

Khalatbari, A., Etude de l'influence du fluide saturant sur la $\checkmark$ iresse des ondes ultrasonores dans les gres, $\mathrm{PhD}$ thesis, 149pp., Univ. of Paris 7, June 1989.

Nowick, A. S., and Berry, B. S., Anelastic relaxation in crystalline solids, Academic Press, Inc., 1972.

Nur, A., and Simmons, G., The effect of viscosity of a fluid phase on velocity in low porosity rocks, Earth Planet. Sci. Lett, 7, 99-108, 1969.

O'Connell, R. J., and Budiansky, B., Viscoelastic properties of fluid-saturated cracked solids, J. Geophys. Res. 82, 5719-5736, 1977.

Tarantola, A., Inverse problem theory. Methods for dan fitting and model parameter estimation, 613 pp., Elsevier, Amsterdam, 1987.

Tittmann, B. R., Bulau, J. R., and Abel-Gawad, M., The role of viscous fluids in the attenuation and velocity of elastic waves in porous rocks, in Physics and chemistry of porous media. edited by Johnson, D. L., and Sen, P. N., pp. 131-143, Am. Inst. of Physics, 1984.

Vo-Thanh, D., Effects of fluid viscosity on shear-wave attenuation in saturated sandstones, Geophysics, 55, 712 . $722,1990$.

Vo-Thanh, D., Effects of fluid viscosity on shear-wave attenuation in partially saturated sandstone, Geophysics. in press.

Walsh, J. B., New analysis of attenuation in partially melted rock, I. Geophys. Res. 74, 4333-4337, 1969.

Weast, R.C., Handbook of chemistry and physics. F-11 and F-35, The Chemical Rubber Co., 1967.

A. Khalatbari, D. Vo-Thanh and J. P. Poirier, Département des Géomatériaux, Institut de Physique du Globe, 4, place Jussieu, 75252 Paris Cedex 05 (France).

(Received December 13, 1990; revised March 11, 1991; accepted March 18, 1991.) 